TITLE:

\title{
Methods to Evaluate Zinc Transport into and out of the Secretory and Endosomal-Lysosomal Compartments in DT40 Cells.
}

$\operatorname{AUTHOR(S):~}$

Kambe, Taiho

\section{CITATION:}

Kambe, Taiho. Methods to Evaluate Zinc Transport into and out of the Secretory and Endosomal-Lysosomal Compartments in DT40 Cells.. Methods in enzymology 2014, 534: 77-92

ISSUE DATE:

2014

URL:

http://hdl.handle.net/2433/180109

RIGHT:

(C) 2014 Elsevier Inc:; This is not the published version. Please cite only the published version.; この論文は出版社版でありません。引用の際に は出版社版をご確認ご利用ください。 
Running title: Zinc transport in subcellular compartments

Methods to evaluate zinc transport into and out of the secretory and endosomal-lysosomal compartments in DT40 cells

Taiho Kambe

Graduate School of Biostudies, Kyoto University, Kyoto 606-8502, Japan

Email: kambe1@kais.kyoto-u.ac.jp

Tel: $+81-75-753-6273$

Keywords: zinc, ZIP (Zrt/Irt-like protein), ZnT (zinc transporter), signaling, secretory and endosomal-lysosomal compartments, DT40, multiple gene disruptions 


\section{Abstract}

Zinc plays crucial roles in diverse biological processes. Recently, in addition to zinc mobilization into and out of the cell, zinc mobilization into and out of intracellular organelles, including the secretory and endosomal-lysosomal compartments, has received growing interest. In vertebrate cells, the Zrt/Irt-like proteins (ZIPs) and zinc transporters (ZnTs) are the two major families of zinc transporters involved in zinc mobilization across cellular membranes. Importantly, nearly half of ZIP and ZnT transporters are localized to subcellular compartments. Thus, to elucidate the numerous zinc-related cellular events, understanding ZIP and $\mathrm{ZnT}$ functions is critical. This chapter describes advanced methods used in our laboratory to examine zinc mobilization. Specifically, genetic and molecular approaches using chicken DT40 cells deficient in multiple $\mathrm{ZnT}$ and ZIP transporters are described. Moreover, procedures to evaluate zinc-related phenotypes caused by the impairment of zinc mobilization into and out of the secretory and endosomal-lysosomal compartments are also described. These methods should be useful in characterizing the roles of zinc in diverse cellular events including endosomal signaling. 


\section{Introduction}

Zinc is an essential trace element required for all living organisms. Analysis

of the proteome reveals that approximately $4-10 \%$ of proteins have potential zinc

binding motifs, which confirms their importance (Andreini, Banci, Bertini and Rosato, 2006). Recent studies have highlighted the various dynamic functions of zinc including structural, catalytic, and regulatory roles in protein function. For example, zinc is essential for the proper regulation of protein kinase signaling, apoptosis signaling, the unfolded protein response (UPR), trafficking of transcription factors, and channel or transporter modulation (Aras and Aizenman, 2011; Colvin, Holmes, Fontaine and Maret, 2010; Fukada and Kambe, 2011; Hershfinkel, Aizenman, Andrews and Sekler, 2010). Moreover, roles of zinc as a second messenger for transducing extracellular signals have been revealed in some types of immune cells (Haase and Rink, 2009; Hirano, Murakami, Fukada, Nishida, Yamasaki and Suzuki, 2008). Thus, growing evidence emphasizes the indispensable nature of zinc for cellular integrity and homeostasis.

Recently, the molecular mechanisms behind how zinc performs its crucial functions are starting to be elucidated, and it has been revealed that zinc mobilized into 
and out of the secretory and endosomal-lysosomal compartments has key cellular roles.

Hence, exploring the molecular functions of zinc transport proteins involved in these processes will be beneficial. In this chapter, the methods to perform basic experiments using vertebrate cells to study zinc transport are described. Specifically, methods to establish knockout cells lacking multiple zinc transporter proteins, and assays for examining their zinc-related phenotypes are described. In the secretory and endosomal-lysosomal compartments, numerous zinc transporter proteins are functional, and therefore determining each one's function at the molecular level will be important. Thus, systems that enable multiple gene disruptions, like those described here, are useful.

2. Intracellular zinc transporters localized to the secretory and endosomal-lysosomal compartments play crucial roles

In vertebrate cells, two zinc transporter family proteins, SLC39A/ZIP and SLC30A/ZnT, are primarily responsible for zinc transport and homeostasis. ZIP transporters import zinc into the cytosol from the extracellular or intracellular 
compartments, while ZnT transporters export cytosolic zinc to extracellular or intracellular compartments (Fukada and Kambe, 2011; Gaither and Eide, 2001; Kambe, Weaver and Andrews, 2008; Lichten and Cousins, 2009) (Fig. 1). Both protein families are expressed in a cell- and tissue-specific manners, are developmentally regulated, and are localized to various subcellular compartments including the cytoplasmic membrane (Fukada and Kambe, 2011; Kambe, 2013; Lemaire, Chimienti and Schuit, 2012). In mammals, 23 ZIP/ZnT proteins are operative (Kambe, Suzuki, Nagao and Yamaguchi-Iwai, 2006), nearly half of which are localized to the secretory and endosomal-lysosomal compartments (Hennigar and Kelleher, 2012; Kambe, 2011) (Table 1). The secretory and endosomal-lysosomal compartments are thought to be important zinc storage sites (Falcon-Perez and Dell'Angelica, 2007; Hogstrand, Kille, Nicholson and Taylor, 2009; McCormick, Velasquez, Finney, Vogt and Kelleher, 2010), and growing evidence has revealed that zinc mobilization into and out of these compartments by ZIP and ZnT transporters is involved in a number of biological processes (Fukada and Kambe, 2011; Fukada, Yamasaki, Nishida, Murakami and Hirano, 2011; Kambe, 2011). 
Evidence for the importance of the role of ZIPs in subcellular zinc efflux is growing. For example, ZIP7 participates in cytosolic signaling by releasing zinc from the endoplasmic reticulum (ER) when phosphorylated by CK2 protein kinase (Taylor, Hiscox, Nicholson, Hogstrand and Kille, 2012). ZIP8 mediates release of zinc from the lysosomes, and plays regulatory roles in T-cell activation, likely through inhibiting calcineurin and thus sustaining CREB activity (Aydemir, Liuzzi, McClellan and Cousins, 2009). ZIP9 is required for the regulation of Akt and Erk activation in the B cell receptor signaling pathway (Taniguchi, Fukunaka, Hagihara, Watanabe, Kamino, Kambe et al., in press), and thought to function in secretory pathway homeostasis (Matsuura, Yamazaki, Yamaguchi-Iwai, Masuda, Nagao, Andrews et al., 2009). ZIP13 is involved in the nuclear translocation of Smad proteins, and thereby functions in the BMP/TGF- $\beta$ signaling pathway by transporting zinc from the Golgi (Fukada, Civic, Furuichi, Shimoda, Mishima, Higashiyama et al., 2008), and ZIP13 also maintains ER homeostasis by regulating zinc release from vesicular stores (Jeong, Walker, Wang, Park, Palmer, Giunta et al., 2012).

Important biological functions associated with ZnTs are also abundant. ZnT1 
was shown to affect intracellular zinc distribution and to down-regulate transcription factors stimulated by MTF-1, c-Jun, and Elk, when localized to the ER by forming a hetero-complex with EVER1 and EVER2 (Lazarczyk, Pons, Mendoza, Cassonnet, Jacob and Favre, 2008). ZnT4, ZnT5, ZnT6, and ZnT7 are all suggested to maintain secretory pathway homeostasis, and regulate zinc-requiring enzyme activities (Fukunaka, Kurokawa, Teranishi, Sekler, Oda, Ackland et al., 2011; McCormick and Kelleher, 2012). ZnT5 and ZnT7 are also engaged in regulation of cytosolic signaling cascades involving PKC/NF-kappaB and PI3K/Akt (Nishida, Hasegawa, Nakae, Oboki, et al., 2009; Zhang, Liang, Guo, Deng, et al., 2013). ZnT10 localizes to the secretory and endosomal compartments (recycling endosomes) and functions in the regulation of ERK signaling by controlling cellular zinc levels (Bosomworth, Thornton, Coneyworth, Ford and Valentine, 2012; Patrushev, Seidel-Rogol and Salazar, 2012). Zinc influx into the endosomal-lysosomal compartments by $\mathrm{ZnT}$ transporters has also been suggested to influence cholesterol metabolism in experiments of ZnT2 overexpression in mutant cells lacking both metallothionein and ZnT1 (Kobayashi, Beuchat, Lindsay, Frias, Palmiter, Sakuraba et al., 1999). Finally, in yeast, drosophila, and plants, the homologs 
of the ZIP and ZnT transporters mentioned above have been shown to be important in various biological processes including ER-associated degradation, Golgi membrane trafficking, regulation of catecholamine production, and auxin metabolism and response (Ellis, Wang, MacDiarmid, Clark, Lyons and Eide, 2004; Fang, Sugiura, Ma, Yada-Matsushima, Umeno and Kuno, 2008; Lasswell, Rogg, Nelson, Rongey and Bartel, 2000; Stathakis, Burton, McIvor, Krishnakumar, Wright and O'Donnell, 1999). Together these data strongly suggest that zinc plays important roles in endosomal signaling, despite the lack of direct evidence.

To further explore roles for zinc in endosomal signaling, approaches using DT40 cells will be helpful because of their high frequency of homologous recombination and their expression of a number of ZIP and ZnT transporters (Table 1). In addition to ZIP and ZnT transporters, several other proteins are thought to function in subcellular zinc transport. The L-type calcium channel is employed for zinc release from the ER after extracellular stimulation (this phenomenon is called "zinc wave") (Yamasaki, Hasegawa, Hojyo, Ohashi, Fukada, Nishida et al., 2012). TRPMLs are thought to be involved in zinc mobilization in the endosomal-lysosomal compartments 
(Eichelsdoerfer, Evans, Slaugenhaupt and Cuajungco, 2010). Importantly, these related proteins are also expressed in DT40 cells.

\section{Establishment of DT40 cells deficient in zinc transporters genes}

\subsection{Basic characteristics of DT40 cells}

The chicken B lymphocyte line DT40 is a well-known model used for gene knockout studies in vertebrate cells, as described in the excellent book Reviews and Protocols in DT40 Research (Buerstedde and Takeda, 2006). The utility of the cells has been shown in a number of functional studies of cellular processes such as DNA damage repair, recombination, and chromosome segregation, as well as B lymphocyte specific functions such as B cell receptor signaling. Several strategies for establishing DT40 cells lacking genes of interest are described elsewhere (Buerstedde and Takeda, 2006). Here, however, the methods used in our laboratory to establish DT40 cells deficient in multiple ZIP and ZnT transporter genes are described. Seven drug-resistant genes are available for gene disruption and gene re-expression in DT40 cells, making cells 
deficient in multiple genes feasible. Alternatively, drug-resistant genes flanked by loxP sequences for excision by Cre recombinase are available if needed.

\subsection{Construction and preparation of knockout vectors}

1. Obtain DNA fragments that will serve as the right and left arms of the knockout vector. The total length of both arms is usually $5 \mathrm{~kb}$ or longer for increased recombination efficiency, but shorter lengths will work. Genetic information for choosing sequences for the arms and designing primers can be found online at http://www.ncbi.nlm.nih.gov/projects/genome/guide/chicken/.

2. Ligate the arms to either side of a drug-resistant cassette containing a promoter, drug-resistant gene, and a polyA addition site. If necessary, the cassette can be flanked by loxP sequences.

3. Linearize 25-30 $\mu \mathrm{g}$ of the constructed plasmid DNA using an appropriate restriction enzyme. The restriction site should be located outside of the homology region.

4. Precipitate the DNA with ethanol and wash with $70 \%$ ethanol, air dry for $10 \mathrm{~min}$, and resuspend in sterile TE to $0.5-1.0 \mu \mathrm{g} / \mu \mathrm{l}$. 


\subsection{Electroporation to introduce knockout vectors and establish DT40 cell lines}

\section{deficient in one gene}

DT40 cells are cultured similarly to mammalian cells, except that chicken serum is required. Specifically, DT40 cells are cultured in RPMI 1640 supplemented with $10 \%$ heat-inactivated fetal calf serum, $1 \%$ chicken serum, and $50 \mu \mathrm{M} 2$-mercaptoethanol at $39.5^{\circ} \mathrm{C}$. DT40 cells can be cultured at $37^{\circ} \mathrm{C}$, but they grow slowly.

1. Spin down $1 \times 10^{7}$ cells and wash with phosphate buffered saline (PBS) once.

2. Resuspend the cells in $0.5 \mathrm{ml}$ PBS and transfer to an electroporation cuvette $(0.4-\mathrm{cm}$ electrode gap).

3. Add $25-30 \mu \mathrm{g}$ of the linearized DNA and incubate on ice for $10 \mathrm{~min}$.

4. Electroporate under conditions of $550 \mathrm{~V}, 25 \mu \mathrm{F}$, and incubate on ice for $10 \mathrm{~min}$.

5. Transfer the cells to a $10-\mathrm{cm}$ dish containing $20 \mathrm{ml}$ of fresh media without selection, and culture the cells overnight at $39.5^{\circ} \mathrm{C}, 5 \% \mathrm{CO}_{2}$ to allow recovery.

6. Resuspend the electroporated cells in 60-80 $\mathrm{ml}$ of fresh media containing selection.

The final concentrations of drugs used are $2 \mathrm{mg} / \mathrm{ml}$ for Neomycin; $0.5 \mathrm{mg} / \mathrm{ml}$ for 
Puromycin; $0.15-0.25 \mathrm{mg} / \mathrm{ml}$ for Hygromycin B; $0.3 \mathrm{mg} / \mathrm{ml}$ for Zeocin; $25 \mu \mathrm{g} / \mathrm{ml}$ for

Blasticidin S; $1 \mathrm{mg} / \mathrm{ml}$ for Histidinol; and $25 \mu \mathrm{g} / \mathrm{ml}$ for Mycophenolic acid.

7. Seed $200 \mu \mathrm{L}$ (about $3 \times 10^{4}$ cells) into each well of three or four 96 -well plates.

8. Select the cells at $39.5^{\circ} \mathrm{C}, 5 \% \mathrm{CO}_{2}$. Stable clones will be visible in about a week.

When the clones grow to about $2 \mathrm{~mm}$ in diameter, transfer them to 24 -well plates with 1

$\mathrm{ml}$ of the same selection medium. The drug does not have to be added to the culture medium once stable clones are established in 24-well plates.

\subsection{Preparation of genomic DNA from the clones}

We recover genomic DNA as described previously (Laird, Zijderveld, Linders, Rudnicki, Jaenisch and Berns, 1991) with slight modification. The recovered DNA prepared by this method is sufficient to perform genomic PCR amplification. Scale up if a large amount of DNA is needed for methods such as Southern blotting.

1. Collect the cells from one well of a 24-well plate into a snap cap microcentrifuge tube, and lyse the cells in $100 \mu \mathrm{l}$ of lysis solution $(200 \mathrm{mM} \mathrm{NaCl}, 20 \mathrm{mM}$ EDTA, 40 $\mathrm{mM}$ Tris- $\mathrm{HCl} \mathrm{pH} 8.0,0.5 \% \mathrm{SDS}, 0.5 \% \beta-\mathrm{ME})$. Add $4 \mu \mathrm{l}$ of Proteinase $\mathrm{K}(20 \mathrm{mg} / \mathrm{ml})$ 
and incubate $2 \mathrm{~h}$ or overnight at $55^{\circ} \mathrm{C}$.

2. Add $1 \mu \mathrm{l}$ of RNase $\mathrm{A}(10 \mathrm{mg} / \mathrm{ml})$ and then incubate for an additional 10 to $15 \mathrm{~min}$ at room temperature.

3. Add $70 \mu \mathrm{l}$ of saturated $\mathrm{NaCl}$, shake well for 15 seconds and let stand for $15 \mathrm{~min}$ on ice. Centrifuge at $12,000 \times \mathrm{g}$ for 15 to $30 \mathrm{~min}$ at $4{ }^{\circ} \mathrm{C}$.

4. Transfer the cleared DNA solution into a clean tube and precipitate it with $250 \mu \mathrm{l}$ of $100 \%$ ethanol. Shake well and centrifuge at $12,000 \times \mathrm{g}$ for $2 \mathrm{~min}$ at $4^{\circ} \mathrm{C}$.

5. Wash the DNA precipitate with $500 \mu \mathrm{l}$ of $70 \%$ ethanol. Centrifuge at $12,000 \times \mathrm{g}$ for 1 $\min$ at $4^{\circ} \mathrm{C}$, and air dry for a few minutes.

6. Dissolve in $15 \mu \mathrm{l}$ of $\mathrm{TE}$, incubate at $55^{\circ} \mathrm{C}$ for $30 \mathrm{~min}$ to $1 \mathrm{~h}$ to get into solution.

\subsection{Establishment of DT40 cells deficient in multiple genes using the estrogen} receptor chimeric Cre-recombinase, CreER.

1. Establish a drug-resistant cell line expressing the estrogen receptor-Cre recombinase fusion protein using the same procedure described in 3.3. The CreER protein is retained within the cytoplasm until driven to the nucleus by a ligand such as 
4-hydroxy-tamoxifen. Only then can the enzyme excise DNA flanked by loxP sites.

2. Treat $\sim 5 \times 10^{4}$ cells in a $6-\mathrm{cm}$ dish containing $5 \mathrm{ml}$ of media with $200 \mathrm{nM}$ 4-hydroxy-tamoxifen for $24-48 \mathrm{~h}$ at $39.5^{\circ} \mathrm{C}, 5 \% \mathrm{CO}_{2}$.

3. Resuspend the cells in fresh medium without the drug, and plate $200 \mu \mathrm{L}$ containing one cell in each well of three 96-well plates.

4. In about a week, transfer the single clones to 24 -well plates containing $1 \mathrm{ml}$ medium without 4-hydroxy-tamoxifen.

5. Confirm excision of the drug-resistant cassette by genomic PCR and check for drug sensitivity of the clones.

6. Electroporate the cells with the next knockout vector using the same procedures described in section 3.3 to establish double transfectants.

7. Repeat the same steps described in section 3.4 to isolate the DNA, and identify DT40 cells with recombination.

8. Repeat steps 2-6 to establish DT40 cells deficient in multiple genes. 
4. Experimental procedures used in studies of DT40 cells deficient in zinc transport.

\subsection{Confirmation of phenotypes of DT40 mutants}

Disruption of ZIP and ZnT transporter genes in DT40 cells causes a number of cellular defects (Kambe, 2011). It is essential to confirm that the defects in the DT40 mutants are complemented by re-expression of the disrupted gene. Exogenous re-expression of the human orthologs is one option, and it is also helpful in determining human gene function.

\subsection{Re-expression of human orthologs of ZIP and ZnT transporters in DT40} mutants

In our laboratory, plasmids harboring an appropriate drug-resistant gene, where the cDNA of interest is under the control of the chicken $\beta$ actin promoter, are usually used for re-expression; however, most mammalian expression systems can be used (Buerstedde and Takeda, 2006). Transfection for re-expression in DT40 mutants is performed in the same way described in section 3.3. 


\subsection{Analyses of complex formation of zinc transporters by immunoprecipitation.}

Zinc transporters function by forming dimers (Bin, Fukada, Hosaka, Yamasaki, Ohashi, Hojyo et al., 2011; Kambe, 2012). Homo or hetero complex formation is easily confirmed by immunoprecipitation (Fukunaka, Suzuki, Kurokawa, Yamazaki, Fujiwara, Ishihara et al., 2009; Suzuki, Ishihara, Migaki, Nagao, Yamaguchi-Iwai and Kambe, 2005b).

1. Establish cell lines expressing the zinc transporter of interest tagged with an antigenic epitope using the electroporation method described in section 3.3.

2. After washing cells once in PBS, lyse the cells $\left(\sim 2 \times 10^{7}\right.$ cells $)$ with $1 \mathrm{ml}$ of Nonidet P-40 lysis buffer (50 mM HEPES-HCl, $\mathrm{pH} 7.4,100 \mathrm{mM} \mathrm{NaCl}, 1.5 \mathrm{mM} \mathrm{MgCl} 2,1 \%$ (v/v) Nonidet P-40) containing protease inhibitors. Rotate the cell lysates for $2 \mathrm{~h}$ at $4^{\circ} \mathrm{C}$, and adjust the concentration to $1 \mu \mathrm{g} / \mu \mathrm{l}$ with Nonidet P-40 lysis buffer. *Note that Nonidet P-40 is also referred to as Igepal.

3. To precipitate the expressed zinc transporter, add antibodies against the epitope to the lysate and rotate it for $1 \mathrm{~h}$. Add $25 \mu \mathrm{l}$ of Protein A- or Protein G-sepharose beads (GE 
Healthcare, Waukesha, WI), and rotate the mixture for an additional $2 \mathrm{~h}$ at $4{ }^{\circ} \mathrm{C}$.

4. Centrifuge the mixture at $400 \times \mathrm{g}$ for $5 \mathrm{~min}$ at $4^{\circ} \mathrm{C}$, and wash the pelleted beads containing the immunoprecipitate three times with Nonidet P-40 lysis buffer. Elute the precipitated proteins in $5 \times$ Ling's solubilizing buffer $(150 \mathrm{mM}$ sucrose, $50 \mathrm{mM}$ Tris-HCl, pH 8.0, 20 mM DTT, 10\% SDS, 5 mM EDTA).

5. Add an equal volume of $2 \times$ Urea buffer ( $8 \mathrm{M}$ urea, $30 \mathrm{mM}$ sucrose, $10 \mathrm{mM}$ Tri s- $\mathrm{HCl}$, $\mathrm{pH} 8.0,4 \mathrm{mM}$ DTT, 2\% SDS, $1 \mathrm{mM}$ EDTA) and incubate at $37^{\circ} \mathrm{C}$ for $30 \mathrm{~min}$ before electrophoresis.

6. For the input fraction of the immunoprecipitation, precipitate an aliquot of the original cell lysate with three volumes of acetone for $2 \mathrm{~h}$ at $-20^{\circ} \mathrm{C}$ and centrifuge at $12,000 \times \mathrm{g}$ for $15 \mathrm{~min}$ at $4^{\circ} \mathrm{C}$. Lyse the pellet with $5 \times$ Ling's solubilizing buffer and treat with $2 \times$ Urea buffer as described above before electrophoresis. This procedure is optional in the case that protein concentrations need to be increased.

\subsection{Transient transfection in DT40 mutants.}

Transient transfection is also possible in DT40 cells (Buerstedde and Takeda, 2006), 
and is useful for analyses using reporter genes to evaluate cytosolic zinc levels or monitor zinc homeostasis in subcellular compartments. Electroporation is usually used, but lipofection is also possible.

1. Spin down $5 \times 10^{6}$ cells and wash with K-PBS $(30.8 \mathrm{mM} \mathrm{NaCl}, 120.7 \mathrm{mM} \mathrm{KCl}, 8.1$ $\mathrm{mM} \mathrm{Na}_{2} \mathrm{HPO}_{4}, 1.46 \mathrm{mM} \mathrm{KH}_{2} \mathrm{PO}_{4}$, and $5 \mathrm{mM} \mathrm{MgCl}_{2}$ ).

2. Resuspend the cells in $0.3 \mathrm{ml} \mathrm{K-PBS}$ in a snap cap microcentrifuge tube.

3. Promptly add $10-15 \mu \mathrm{g}$ of plasmid DNA diluted in $0.2 \mathrm{ml} \mathrm{K-PBS}$ to the cells. After mixing gently, transfer to an electroporation cuvette ( $0.4 \mathrm{~cm}$ electrode gap). Incubate on ice for $10 \mathrm{~min}$.

4. Electroporate under conditions of $600 \mathrm{~V}, 25 \mu \mathrm{F}$, and incubate on ice for $10 \mathrm{~min}$.

5. Transfer the cells to a $10-\mathrm{cm}$ dish containing $20 \mathrm{ml}$ of fresh media, and culture at $39.5^{\circ} \mathrm{C}, 5 \% \mathrm{CO}_{2}$. Move the cells into multiwell plates after a several hour recovery period, if the cells will need to be treated .

\section{Functional analysis of zinc mobilization into or out of the secretory and}

endosomal-lysosomal compartments. 


\subsection{Immunofluorescence analysis of zinc mobilization in DT40 mutants deficient in ZIP and ZnT transporters.}

There are a number of fluorescent zinc probes with different affinities to zinc (Huang and Lippard, 2012) that can be used as reporters. Upon zinc binding, these probes elicit a bright fluorescent signal, which can be used to measure zinc levels or follow subcellular zinc release in live cells.

1. Wash approximately $5 \times 10^{5}$ cells with cold Hanks' balanced salt solution (HBSS) twice and then resuspend them in HBSS containing the zinc fluorescent probe (typically $\mu \mathrm{M}$ order). Treat the cells with $\mathrm{ZnSO}_{4}$ if more zinc is needed in the cells and subcellular compartments. TPEN, a zinc chelator, is also added to ensure that the fluorescence signal results from zinc binding to the probe.

2. Incubate the stained cells on coverslips coated with poly-L lysine in a humidified chamber for $30 \mathrm{~min}$ at $37^{\circ} \mathrm{C}$

3. Fix the stained cells on the coverslips with $4 \%$ paraformaldehyde. Cytospin (Thermo Scientific) is also available to fix the cells on cover glass (Matsuura et al., 2009).

4. Observe the stained cells under a fluorescence microscope. 


\subsection{Monitoring cytosolic zinc levels and zinc-related homeostasis in DT40 cells.}

$M T$ mRNA has been used to elucidate cytosolic zinc levels in mammalian cells because of its rapid induction in response to zinc. Similar procedures are possible in DT40 cells because chicken $M T$ mRNA is regulated in the same way as it is in mammalian cells (Matsuura et al., 2009). Other zinc-regulated responses such as the UPR are also conserved in DT40 cells (Ishihara, Yamazaki, Ishida, Suzuki, Oda, Nagao et al., 2006). Assessment of these events can be used to evaluate intracellular zinc. In fact, most mammalian reporter plasmids are functional in DT40 cells (Buerstedde and Takeda, 2006). For example, the MT-luciferase reporter used to evaluate cytosolic zinc (Kimura, Li, Okumura, Itoh, Nakanishi, Sone et al., 2008), and the 5xATF6 luciferase used to monitor the UPR (Wang, Shen, Arenzana, Tirasophon, Kaufman and Prywes, 2000) are both effective in DT40 cells and can be used to assess changes in zinc transport (Ishihara et al., 2006; Jeong et al., 2012).

\subsection{Evaluation of zinc status in subcellular compartments using zinc-dependent}


enzymes such as alkaline phosphatase.

The activity of alkaline phosphatase (ALP) is also zinc-dependent, and thus is useful to assess the zinc status in the secretory compartments of vertebrates (Jeong et al., 2012; Suzuki, Ishihara, Migaki, Matsuura, Kohda, Okumura et al., 2005a), or in the endosomal-lysosomal compartments (vacuoles) in yeast (Qiao, Ellis, Steffen, Wu and Eide, 2009). For example, activation of the endogenous non-specific ALP (TNAP) or the exogenously expressed placenta ALP (PLAP) is impaired in DT40 cells deficient in ZnT5, ZnT6, and ZnT7 genes (Fig. 2).

\subsection{Measurement of alkaline phosphatase activity}

1. Lyse approximately $0.5-1 \times 10^{6}$ cells in $100 \mu \mathrm{l}$ ALP lysis buffer $(10 \mathrm{mM}$ Tris-HCl, $\mathrm{pH} 7.5,0.5 \mathrm{mM} \mathrm{MgCl}_{2}$ and $0.1 \%$ Triton-X 100).

2. Incubate the lysate at $65^{\circ} \mathrm{C}$ for $30 \mathrm{~min}$ to inactivate TNAP if measuring PLAP (placenta-derived ALP) activity (Fig. 2). TNAP is thermosensitive, while PLAP is thermoresistant.

3. Incubate 1-5 $\mu \mathrm{g}$ of the lysate in triplicate in a 96-well plate for $10 \mathrm{~min}$ at room 
temperature. In addition, prepare dilutions of purified alkaline phosphatase for a standard curve.

4. Add $100 \mu \mathrm{l}$ of substrate solution $(2 \mathrm{mg} / \mathrm{ml} p$-nitrophenyl phosphate in $1 \mathrm{M}$ diethanolamine buffer, $\mathrm{pH} 9.8$ containing $0.5 \mathrm{mM} \mathrm{MgCl}_{2}$ ) using a multi-channel pipette, mix well using microplate mixer, and incubate for 5-10 $\mathrm{min}$ at room temperature before measuring the activity.

5. Measure the $p$-nitrophenol released by TNAP/PLAP using the $405 \mathrm{~nm}$ absorbance (yellow color).

\section{Concluding remarks}

Recent findings indicate that zinc mobilization across the membranes of subcellular compartments by both ZIP and ZnT transporters acts as a fundamental regulator of a variety of biological functions (Fukada and Kambe, 2011; Fukada et al., 2011; Haase and Rink, 2009; Kambe, 2011). Indeed, zinc mobilization into and out of the endosomes is thought to play crucial roles in endosomal signaling. However, many details still need to be determined. The methods described in this chapter will be helpful in the 
clarification of the functions of zinc in endosomal signaling. They are focused on the use of DT40 cells, but could also be widely applied to studies using mammalian cells deficient in ZIP or ZnT transporters. 
ACKNOWLEDGMENTS

I thank Drs. Shunichi Takeda and Minoru Takata for providing us the DT40 cells and the protocol for gene disruption experiments. This work was supported by Grants-in-Aid from the Ministry of Education, Culture, Sports, Science and Technology of Japan

\section{REFERENCES}

Andreini, C., Banci, L., Bertini, I., and Rosato, A. (2006). Zinc through the three domains of life. J Proteome Res 5, 3173-3178.

Aras, M.A., and Aizenman, E. (2011). Redox regulation of intracellular zinc: molecular signaling in the life and death of neurons. Antioxid Redox Signal 15, 2249-2263.

Aydemir, T.B., Liuzzi, J.P., McClellan, S., and Cousins, R.J. (2009). Zinc transporter ZIP8 (SLC39A8) and zinc influence IFN-gamma expression in activated human T cells.

J Leukoc Biol 86, 337-348.

Bin, B.H., Fukada, T., Hosaka, T., Yamasaki, S., Ohashi, W., Hojyo, S., et al. (2011).

Biochemical characterization of human ZIP13 protein: a homo-dimerized zinc 
transporter involved in the spondylocheiro dysplastic Ehlers-Danlos syndrome. J Biol

Chem 286, 40255-40265.

Bosomworth, H.J., Thornton, J.K., Coneyworth, L.J., Ford, D., and Valentine, R.A.

(2012). Efflux function, tissue-specific expression and intracellular trafficking of the $\mathrm{Zn}$

transporter ZnT10 indicate roles in adult Zn homeostasis. Metallomics. 4, 771-779.

Buerstedde, J.M and Takeda, S (Eds.), (2006). Reviews and Protocols in DT40

Research (Subcellular Biochemistry, Vol. 40). New York: Springer.

Colvin, R.A., Holmes, W.R., Fontaine, C.P., and Maret, W. (2010). Cytosolic zinc

buffering and muffling: their role in intracellular zinc homeostasis. Metallomics 2,

306-317.

Eichelsdoerfer, J.L., Evans, J.A., Slaugenhaupt, S.A., and Cuajungco, M.P. (2010). Zinc

dyshomeostasis is linked with the loss of mucolipidosis IV-associated TRPML1 ion

channel. J Biol Chem 285, 34304-34308.

Ellis, C.D., Wang, F., MacDiarmid, C.W., Clark, S., Lyons, T., and Eide, D.J. (2004).

Zinc and the Msc2 zinc transporter protein are required for endoplasmic reticulum

function. J Cell Biol 166, 325-335. 
Falcon-Perez, J.M., and Dell'Angelica, E.C. (2007). Zinc transporter 2 (SLC30A2) can suppress the vesicular zinc defect of adaptor protein 3-depleted fibroblasts by promoting zinc accumulation in lysosomes. Exp Cell Res 313, 1473-1483.

Fang, Y., Sugiura, R., Ma, Y., Yada-Matsushima, T., Umeno, H., and Kuno, T. (2008).

Cation diffusion facilitator Cis4 is implicated in Golgi membrane trafficking via regulating zinc homeostasis in fission yeast. Mol Biol Cell 19, 1295-1303.

Fukada, T., Civic, N., Furuichi, T., Shimoda, S., Mishima, K., Higashiyama, H., et al. (2008). The zinc transporter SLC39A13/ZIP13 is required for connective tissue development; its involvement in BMP/TGF-beta signaling pathways. PLoS ONE 3, e3642.

Fukada, T., and Kambe, T. (2011). Molecular and genetic features of zinc transporters in physiology and pathogenesis. Metallomics 3, 662-674.

Fukada, T., Yamasaki, S., Nishida, K., Murakami, M., and Hirano, T. (2011). Zinc homeostasis and signaling in health and diseases : Zinc signaling. J Biol Inorg Chem 16, $1123-1134$. 
Fukunaka, A., Kurokawa, Y., Teranishi, F., Sekler, I., Oda, K., Ackland, M.L., et al.

(2011). Tissue Nonspecific Alkaline Phosphatase Is Activated via a Two-step

Mechanism by Zinc Transport Complexes in the Early Secretory Pathway. J Biol Chem

286, 16363-16373.

Fukunaka, A., Suzuki, T., Kurokawa, Y., Yamazaki, T., Fujiwara, N., Ishihara, K., et al. (2009). Demonstration and characterization of the heterodimerization of ZnT5 and

ZnT6 in the early secretory pathway. J Biol Chem 284, 30798-30806.

Gaither, L.A., and Eide, D.J. (2001). Eukaryotic zinc transporters and their regulation.

Biometals 14, 251-270.

Haase, H., and Rink, L. (2009). Functional significance of zinc-related signaling pathways in immune cells. Annu Rev Nutr 29, 133-152.

Hennigar, S.R., and Kelleher, S.L. (2012). Zinc networks: the cell-specific compartmentalization of zinc for specialized functions. Biol Chem 393, 565-578.

Hershfinkel, M., Aizenman, E., Andrews, G., and Sekler, I. (2010). Zinc bells rang in Jerusalem! Sci Signal 3, mr2. 
Hirano, T., Murakami, M., Fukada, T., Nishida, K., Yamasaki, S., and Suzuki, T. (2008).

Roles of zinc and zinc signaling in immunity: zinc as an intracellular signaling molecule.

Adv Immunol 97, 149-176.

Hogstrand, C., Kille, P., Nicholson, R.I., and Taylor, K.M. (2009). Zinc transporters and cancer: a potential role for ZIP7 as a hub for tyrosine kinase activation. Trends Mol Med $15,101-111$

Huang, Z., and Lippard, S.J. (2012). Illuminating mobile zinc with fluorescence from cuvettes to live cells and tissues. Methods Enzymol 505, 445-468.

Ishihara, K., Yamazaki, T., Ishida, Y., Suzuki, T., Oda, K., Nagao, M., et al. (2006).

Zinc transport complexes contribute to the homeostatic maintenance of secretory pathway function in vertebrate cells. J Biol Chem 281, 17743-17750.

Jeong, J., Walker, J.M., Wang, F., Park, J.G., Palmer, A.E., Giunta, C., et al. (2012). Promotion of vesicular zinc efflux by ZIP13 and its implications for spondylocheiro dysplastic Ehlers-Danlos syndrome. Proc Natl Acad Sci U S A 109, E3530-3538. Kambe, T. (2011). An overview of a wide range of functions of $\mathrm{ZnT}$ and Zip zinc transporters in the secretory pathway. Biosci Biotechnol Biochem 75, 1036-1043. 
Kambe, T. (2012). Molecular Architecture and Function of ZnT Transporters. Curr Top

Membr 69, 199-220.

Kambe, T., (2013). Regulation of zinc transport. In, R. A. Scott \& V. Culotta (Vol. Eds),

Encyclopedia of Inorganic and Bioinorganic Chemistry, Metals in Cells, Hoboken, NJ:

John Wiley and Sons, Inc. in press.

Kambe, T., Suzuki, T., Nagao, M., and Yamaguchi-Iwai, Y. (2006). Sequence similarity and functional relationship among eukaryotic ZIP and CDF transporters. Genomics

Proteomics Bioinformatics 4, 1-9.

Kambe, T., Weaver, B.P., and Andrews, G.K., 2008. The genetics of essential metal homeostasis during development. Genesis 46, 214-228.

Kimura, T., Li, Y., Okumura, F., Itoh, N., Nakanishi, T., Sone, T., et al. (2008).

Chromium(VI) inhibits mouse metallothionein-I gene transcription by preventing the zinc-dependent formation of an MTF-1-p300 complex. Biochem J 415, 477-482.

Kobayashi, T., Beuchat, M.H., Lindsay, M., Frias, S., Palmiter, R.D., Sakuraba, H., et al. (1999). Late endosomal membranes rich in lysobisphosphatidic acid regulate cholesterol transport. Nat Cell Biol 1, 113-118. 
Laird, P.W., Zijderveld, A., Linders, K., Rudnicki, M.A., Jaenisch, R., and Berns, A.

(1991). Simplified mammalian DNA isolation procedure. Nucleic Acids Res 19, 4293.

Lasswell, J., Rogg, L.E., Nelson, D.C., Rongey, C., and Bartel, B. (2000). Cloning and characterization of IAR1, a gene required for auxin conjugate sensitivity in Arabidopsis.

Plant Cell 12, 2395-2408.

Lazarczyk, M., Pons, C., Mendoza, J.A., Cassonnet, P., Jacob, Y., and Favre, M. (2008).

Regulation of cellular zinc balance as a potential mechanism of EVER-mediated

protection against pathogenesis by cutaneous oncogenic human papillomaviruses. $J$ Exp

Med 205, 35-42.

Lemaire, K., Chimienti, F., and Schuit, F. (2012). Zinc transporters and their role in the pancreatic $\beta$-cell. J Diabetes Investig, 3, 202-211.

Lichten, L.A., and Cousins, R.J. (2009). Mammalian zinc transporters: nutritional and physiologic regulation. Annu Rev Nutr 29, 153-176.

Matsuura, W., Yamazaki, T., Yamaguchi-Iwai, Y., Masuda, S., Nagao, M., Andrews, G.K., et al. (2009). SLC39A9 (ZIP9) regulates zinc homeostasis in the secretory 
pathway: characterization of the ZIP subfamily I protein in vertebrate cells. Biosci

Biotechnol Biochem 73, 1142-1148.

McCormick, N., Velasquez, V., Finney, L., Vogt, S., and Kelleher, S.L. (2010). X-ray

fluorescence microscopy reveals accumulation and secretion of discrete intracellular

zinc pools in the lactating mouse mammary gland. PLoS One 5, e11078.

McCormick, N.H., and Kelleher, S.L. (2012). ZnT4 provides zinc to zinc-dependent

proteins in the trans-Golgi network critical for cell function and $\mathrm{Zn}$ export in mammary epithelial cells. Am J Physiol Cell Physiol 303, C291-297.

Nishida, K., Hasegawa, A., Nakae, S., Oboki, K., Saito, H., Yamasaki, S., et al. (2009).

Zinc transporter Znt5/Slc30a5 is required for the mast cell-mediated delayed-type

allergic reaction but not the immediate-type reaction. $J$ Exp Med 206, 1351-1364.

Patrushev, N., Seidel-Rogol, B., and Salazar, G. (2012). Angiotensin II Requires Zinc

and Downregulation of the Zinc Transporters ZnT3 and ZnT10 to Induce Senescence of

Vascular Smooth Muscle Cells. PLoS One 7, e33211. 
Qiao, W., Ellis, C., Steffen, J., Wu, C.Y., and Eide, D.J. (2009). Zinc status and vacuolar zinc transporters control alkaline phosphatase accumulation and activity in Saccharomyces cerevisiae. Mol Microbiol 72, 320-334.

Stathakis, D.G., Burton, D.Y., McIvor, W.E., Krishnakumar, S., Wright, T.R., and O'Donnell, J.M. (1999). The catecholamines up (Catsup) protein of Drosophila melanogaster functions as a negative regulator of tyrosine hydroxylase activity. Genetics 153, 361-382.

Suzuki, T., Ishihara, K., Migaki, H., Matsuura, W., Kohda, A., Okumura, K., et al. (2005a). Zinc transporters, ZnT5 and ZnT7, are required for the activation of alkaline phosphatases, zinc-requiring enzymes that are glycosylphosphatidylinositol-anchored to the cytoplasmic membrane. J Biol Chem 280, 637-643.

Suzuki, T., Ishihara, K., Migaki, H., Nagao, M., Yamaguchi-Iwai, Y., and Kambe, T. (2005b). Two different zinc transport complexes of cation diffusion facilitator proteins localized in the secretory pathway operate to activate alkaline phosphatases in vertebrate cells. J Biol Chem 280, 30956-30962. 
Taniguchi, M., Fukunaka, A., Hagihara, M., Watanabe, K., Kamino, S., Kambe, T., et al.

(2013). Essential role of the zinc transporter ZIP9/SLC39A9 in regulating the

activations of Akt and Erk in B-cell receptor signaling pathway in DT40 cells. PLoS

$O N E$ in press.

Taylor, K.M., Hiscox, S., Nicholson, R.I., Hogstrand, C., and Kille, P. (2012). Protein

Kinase CK2 Triggers Cytosolic Zinc Signaling Pathways by Phosphorylation of Zinc

Channel ZIP7. Sci Signal 5, ra11.

Wang, Y., Shen, J., Arenzana, N., Tirasophon, W., Kaufman, R.J., and Prywes, R.

(2000). Activation of ATF6 and an ATF6 DNA binding site by the endoplasmic

reticulum stress response. J Biol Chem 275, 27013-27020.

Yamasaki, S., Hasegawa, A., Hojyo, S., Ohashi, W., Fukada, T., Nishida, K., et al.

(2012). A Novel Role of the L-Type Calcium Channel alpha(1D) Subunit as a

Gatekeeper for Intracellular Zinc Signaling: Zinc Wave. PLoS One 7, e39654.

Zhang, X., Liang, D., Guo, B., Deng, W., Chi, Z.H., Cai, Y., et al. (2012). Zinc

Transporter 5 And Zinc Transporter 7 Induced by High Glucose Protects Peritoneal

Mesothelial Cells From Undergoing Apoptosis. Cell Signal. 
Table 1. Expression of zinc transporters located in the subcellular compartments in DT40 cells

\begin{tabular}{|c|c|c|}
\hline Gene & Reported subcellular localization & Expression in DT40 cells \\
\hline ZnT1 & Mostly localized to the plasma membrane, ER & + \\
\hline$Z n T 2$ & endosomes/lysosomes & $-*$ \\
\hline ZnT4 & endosomes/lysosomes, TGN & + \\
\hline ZnT5 & early secretory pathway, vesicles & + \\
\hline ZnT6 & early secretory pathway, vesicles & + \\
\hline$Z n T 7$ & early secretory pathway, TGN & + \\
\hline $\mathrm{ZnT} 10$ & Golgi apparatus, recycling endosomes & - \\
\hline ZIP7 & ER, Golgi apparatus & - \\
\hline ZIP8 & plasma membrane, endosomes/lysosomes & + \\
\hline ZIP9 & Golgi apparatus & + \\
\hline ZIP13 & Golgi apparatus, vesicles & + \\
\hline
\end{tabular}

*, The cDNA fragment was detected by RT-PCR, but the functional ORF was not. This table omits the zinc transporters that show tissue- or cell-specific expression patterns. 


\section{Figure Legends}

Fig. 1. Regulation of zinc into and out of the secretory and endosomal-lysosomal compartments by ZIP and ZnT transporters.

ZIP and ZnT transporters localized to the secretory and endosomal-lysosomal compartments regulate zinc homeostasis in both the cytosol and the lumen of the subcellular compartments. ER, endoplasmic reticulum; TGN, trans-Golgi network.

Fig. 2. PLAP activity in DT40 cells deficient in both $Z n T 5$ and $Z n T 7$ genes.

A, Zinc-dependent PLAP activity in DT40 cells. N, normal medium; C, zinc-deficient medium; $\mathrm{C}+2$ and $\mathrm{C}+50$, zinc-deficient medium supplemented with 2 and $50 \mu \mathrm{M}$ $\mathrm{ZnSO}_{4}$, respectively. B, PLAP activity in DT40 cells deficient in both ZnT5 and ZnT7

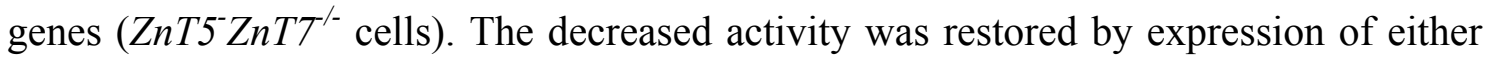
hZnT5 or hZnT7. C and D, PLAP protein is located in the cytoplasmic membrane in $Z n T 5^{-} \mathrm{ZnT7^{-/ }}$ cells, despite having little activity. Modified from (Suzuki et al., 2005a). 


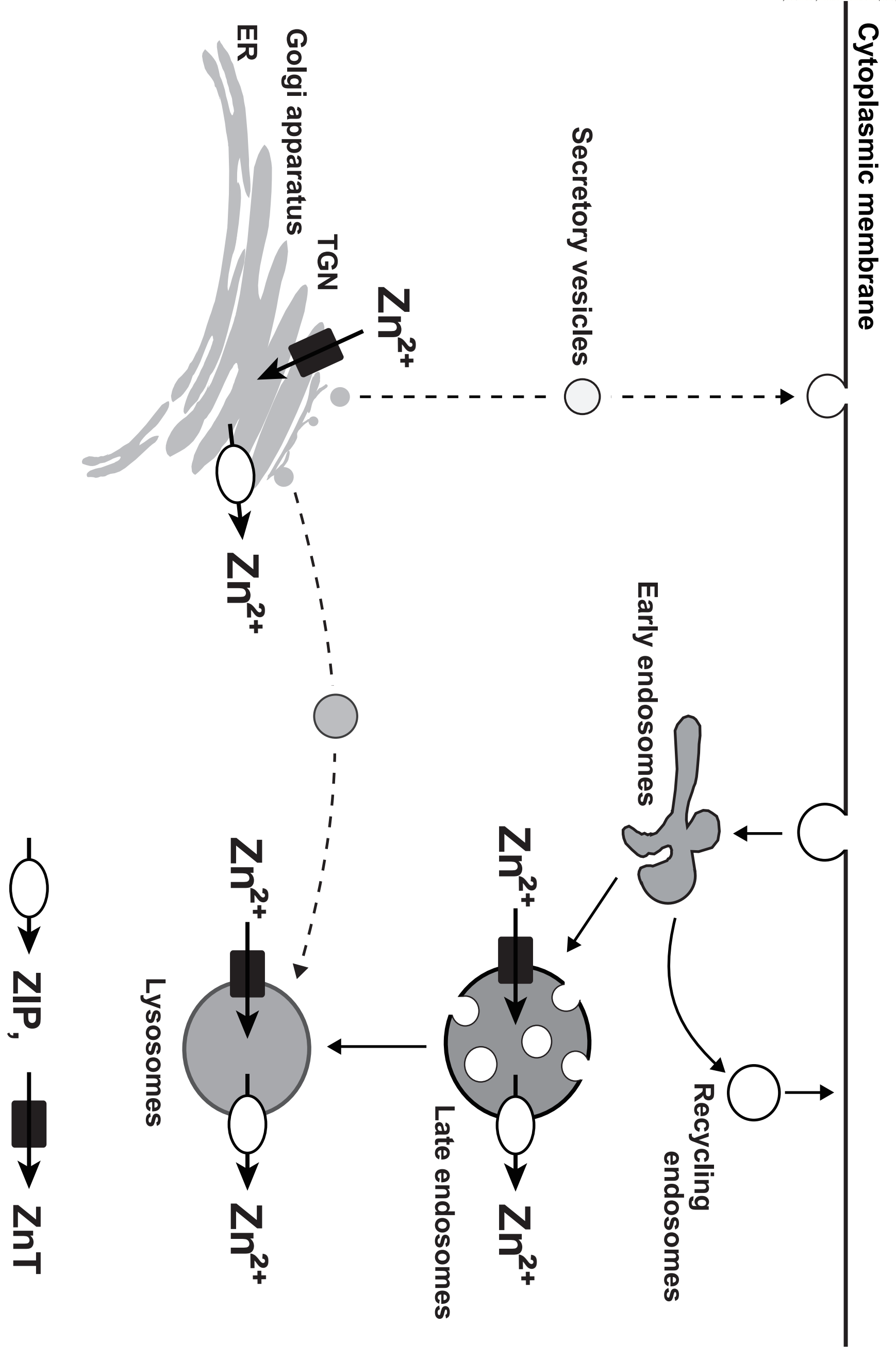

$\frac{\pi}{6}$ 
A

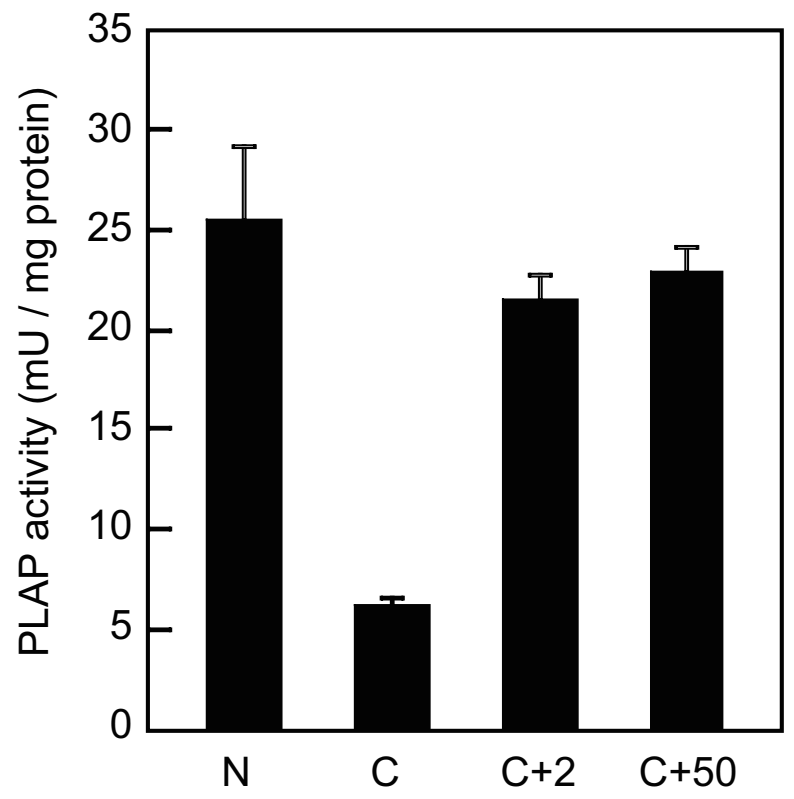

C

PLAP

Calnexin

$$
\text { WT } \frac{-\mathrm{hZnT5} \text { hZnT7 }}{\mathrm{ZnT5}^{-} \mathrm{ZnT7}^{-/-}}
$$

B

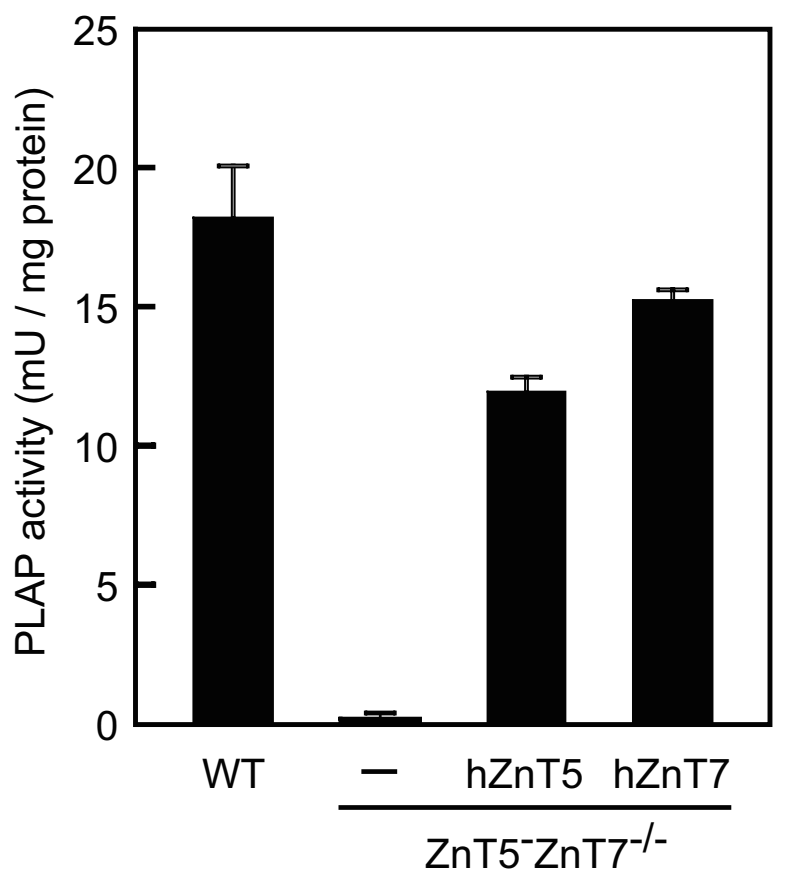

D

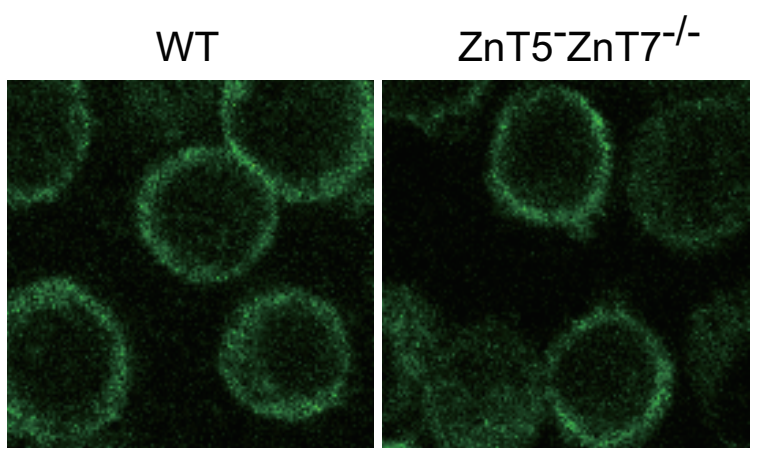

